\title{
Diagnosis and Management of Frailty in Primary Health Care
}

\author{
Chang Won Won* \\ Department of Family Medicine, Kyung Hee University School of Medicine, Seoul, Korea
}

Disability in older adults has become a significant burden, both individually and socially, due to the rapidly aging population in Korea. It is important to manage both frailty and chronic diseases to delay disability. Frailty, which is considered to be a transition phase between healthy status and disability, is defined as a significant decline in functional reserves of multiple organ systems and the resultant extreme vulnerability to stressors, leading to a higher risk of adverse health-related outcomes. The frailty phenotype and frailty index are the most commonly used methods to diagnose frailty. Frailty is related to physical, psychological, cognitive, and social dysfunction, and is sometimes caused by chronic disease. Therefore, primary care providers are ideally situated to incorporate the concept of frailty into their practice, as they are champions in comprehensive care. Although the identification and treatment of frailty is not yet standard practice in primary care, primary care physicians must use the electronic frailty index to identify frailty in all the patients aged $\geq 65$ years in the United Kingdom. In Canada, some insurance companies and governments are using a similar program, which is called the Community Actions and Resources Empowering Seniors model. The clinical practice guidelines of the International Conference of Frailty and Sarcopenia Research, as well as some additional references, will be introduced. Here, we review the current literature on how to diagnose and manage frailty in primary care.

Keywords: Frailty; Primary Health Care; Diagnosis; Management

Received: May 27, 2020, Revised: June 28, 2020, Accepted: July 7, 2020

${ }^{*}$ Corresponding Author: Chang Won Won https://orcid.org/0000-0002-6429-4461

Tel: +82-2-958-8697, Fax: +82-2-958-8699, E-mail: chunwon@khmc.or.kr 


\section{INTRODUCTION}

As the population of Korea is rapidly aging due to low fertility and a long-life span, ${ }^{1)}$ comorbidities and disability of older adults have increased. Disability is linked to functional dependency on caregivers and results in significant long-term health care expenses. Health care expenditure for the older population has increased more rapidly than for younger adults. ${ }^{2}$ Although the development of medical science has succeeded in controlling many diseases, increasing lifespan, and delaying the onset of disability to some degree, ${ }^{3)}$ it does not entirely reduce the disability burden in older age.

What else can help prevent or delay the onset of disability in the older population? To keep older adults functionally capable, it is imperative not just to treat those with comorbidities. ${ }^{3)}$ Disability means severe functional impairments that result in assistance being required to accomplish basic activities of daily living. Contrastingly, frailty is considered to be an impairment in body function. Therefore, frailty is a transition phase between healthy or robust status and disability. Therefore, to delay the onset of disability, managing and preventing frailty is important.

Frailty becomes a more common health problem with age. The prevalence of frailty in community-dwelling older adults varies from $4.9 \%$ to $27.3 \%$ around the world ${ }^{4)}$ and increases to $50 \%$ in those $>80$ years of age. ${ }^{5)}$ As such, frailty is becoming increasingly important for physicians to consider when taking care of older patients. Here, we review how to diagnose and manage frailty in primary care.

\section{FRAILTY: EXTENSION OF THE DISEASE MODEL TO FUNCTION CONCEPT}

The World Health Organization (WHO) has defined healthy ageing "as more than just the absence of disease, and the process of developing and maintaining the functional ability that enables wellbeing in older age irrespective disease." ${ }^{\text {(6) }}$ Functional ability is about having the capability to carry out activities that people value. Functional ability is made up of the intrinsic capacity or functional reserve of the individual. Therefore, healthy aging is considered to occur even in individuals that have a chronic disease as long as they maintain daily functional ability. Contrastingly, if an older adult does not have a chronic disease but cannot maintain their daily functional ability, then this is considered not to be healthy aging. The WHO asserted that "frailty" is a risk against healthy aging.

Therefore, frailty interventions should focus on function, irrespective of comorbidities. Nowadays, practitioners are facing a paradigm shift from a disease to function model, with a move from organ-based medicine to functional medicine. ${ }^{7)}$

\section{DEFINITION OF FRAILTY}

Frailty is defined as a significant decline in functional reserve, resistance, and resilience of multiple organ systems, and the resultant ex- treme vulnerability of the individual to endogenous and exogenous stressors (like infection, injury or surgery, or some medicines), leading to a higher risk of accelerated functional decline and adverse healthrelated outcomes (Figure 1). ${ }^{8)}$ Functional decline is usually caused by the interaction of progressive age-related changes in organs and pathologies of chronic diseases, consequently leading to decreased functional reserve capacities. The adverse health-related outcomes caused by frailty include falls, delirium, immobility or disability and consequently hospitalizations, institutionalization, and mortality.-10)

Although any organ may show accelerated functional decline driven by a stressor, the skeletal muscles, and brain are the most common. Therefore, muscle weakness (sarcopenia) and delirium (or cognitive decline) are the most common presentations of frailty. Multi-organ interventions are important for the management of frailty.

\section{DIAGNOSIS OF FRAILTY}

The most common ways of diagnosing frailty are the phenotypic and deficit accumulation approaches.

\section{Frailty Phenotype}

The phenotypic approach, or Fried's frailty phenotype, classifies a person as frail if three or more of the five frailty items are present. The five items are (1) slow walking speed, (2) impaired grip strength, (3) declining physical activity levels, (4) exhaustion, and (5) unintended weight loss. The presence of just one or two of the five items is defined as prefrailty, and none of them indicates healthy or robust. ${ }^{11)}$ The Fried frailty phenotype focuses on physical domains, and so it is recognized as the physical frailty phenotype. The cut-off values for grip strength and gait speed of the five components were suggested by Fried based on the Cardiovascular Health Study. ${ }^{11)}$ Won et al. ${ }^{12)}$ suggested criteria for frailty among Korean older adults based on data of Korean Frailty and Aging Cohort Study as follows (Table 1). ${ }^{13)}$

\section{Frailty Index}

The other approach to defining frailty is the frailty index (FI), which is a sum of health deficits. In FI, health deficits can be any physical or

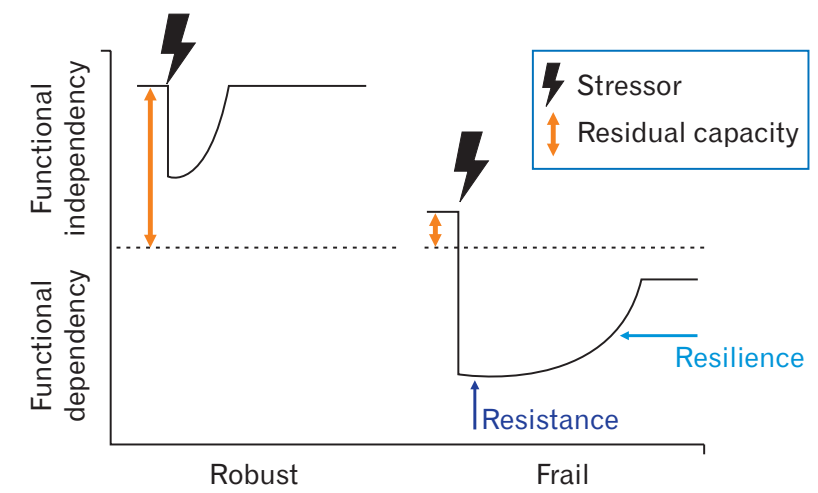

Figure 1. Concept of frailty and its vulnerability to stressors in terms of functional dependency. Modified from Clegg et al. Lancet 2013;381:752-62. ${ }^{8}$ ) 
Table 1. Five items of Fried's frailty phenotype and its cutoff reference (suggested by Korean Frailty and Aging Cohort Study)

\begin{tabular}{|c|c|}
\hline Item & Cutoff reference \\
\hline Unintentional weight loss & Defined as a "yes" response to the question: "In the last year, have you lost more than $4.5 \mathrm{~kg}$ unintentionally?" \\
\hline Weakness & 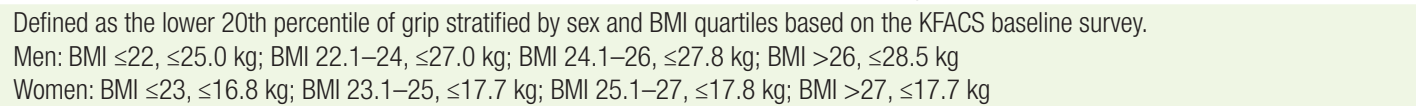 \\
\hline Self-reported exhaustion & $\begin{array}{l}\text { Defined as a "yes" response to either of the following statements from the Center for Epidemiological Studies-Depression scale on } 3 \text { or more } \\
\text { days per week: "I felt that everything I did was an effort" and "I could not get going." }\end{array}$ \\
\hline Slowness & $\begin{array}{l}\text { Walking speed over } 4 \mathrm{~m} \text { was measured using an automatic timer with acceleration and deceleration phases of } 1.5 \mathrm{~m} \text {. The lowest } 20 \% \text { of gait } \\
\text { speed stratified by sex and height based on KFACS data was suggested as a cut-off. } \\
\text { Men: height } \leq 165 \mathrm{~cm}, \leq 0.93 \mathrm{~m} / \mathrm{s} \text {; height }>165 \mathrm{~cm}, \leq 0.98 \mathrm{~m} / \mathrm{s} \\
\text { Women: height } \leq 152 \mathrm{~cm}, \leq 0.85 \mathrm{~m} / \mathrm{s} \text {; height }>152 \mathrm{~cm}, \leq 0.93 \mathrm{~m} / \mathrm{s}\end{array}$ \\
\hline Low physical activity & $\begin{array}{l}\text { Energy expenditure estimates (kcal/wk) were calculated using the IPAQ and metabolic equivalent scores were derived from vigorous, moderate, } \\
\text { and mild activities in the questionnaire. Low physical activity level was defined as }<494.65 \mathrm{kcal} \text { for men and }<283.50 \mathrm{kcal} \text { for women, } \\
\text { corresponding to the lowest } 20 \% \text { of the total energy consumed in a population-based Korean survey of older adults from among the general } \\
\text { population }^{13)}\end{array}$ \\
\hline
\end{tabular}

BMI, body mass index; KFACS, Korean Frailty and Aging Cohort Study; IPAQ, International Physical Activity Questionnaire.

mental disability, symptom or sign, disease, or laboratory finding. ${ }^{14)}$ The rationale for counting health deficits in FI is straightforward: the more health problems an individual has, the greater their risk of being frail and having adverse health outcomes. The index is often expressed as the number of deficits present divided by the total number of deficits considered. For example, if 40 deficits were considered, and 10 were present in a given person, that person's FI would be $10 / 40=0.25$. Therefore, FI ranges from 0 to 1 , and the higher the FI score, the frailer the person is considered to be.

FI is sometimes calculated based on a comprehensive geriatric assessment (CGA). Frailty is related to physical, psychological, cognitive, sensory, and social dysfunction. ${ }^{15)}$

The standardized CGA used for the FI can comprise assessments in 10 standard domains: (1) cognitive status including delirium or dementia; (2) mood and motivation; (3) communication including vision, hearing, speech; (4) mobility; (5) balance; (6) bowel function; (7) bladder function; (8) instrumental activities of daily livings and activities of daily livings; (9) nutrition; and (10) social resources.

Frailty is also known to be highly associated with hypertension, diabetes mellitus, cancer (other than minor skin cancers), chronic lung disease, heart attacks, congestive heart failure, angina, asthma, arthritis, stroke, and kidney disease. ${ }^{16,17)}$

If frailty is caused by any disease, it is sometimes called secondary frailty. Otherwise, it is called primary frailty. As shown in Figure 2, onequarter to one-third of frailty cases are not associated with a comorbidity.

Based on these principles, Theou et al. ${ }^{18)}$ constructed FI with 56 variables that were chosen from a CGA adapted for use in primary care. Meanwhile, the author and colleagues recently developed and validated the Korean frailty index for primary care with 53 deficits. ${ }^{19)} \mathrm{A}$ comparison of the frailty phenotype and FI is summarized in Table 2.

\section{SCREENING FOR FRAILTY}

To diagnose frailty using the Fried frailty phenotype, gait speed and

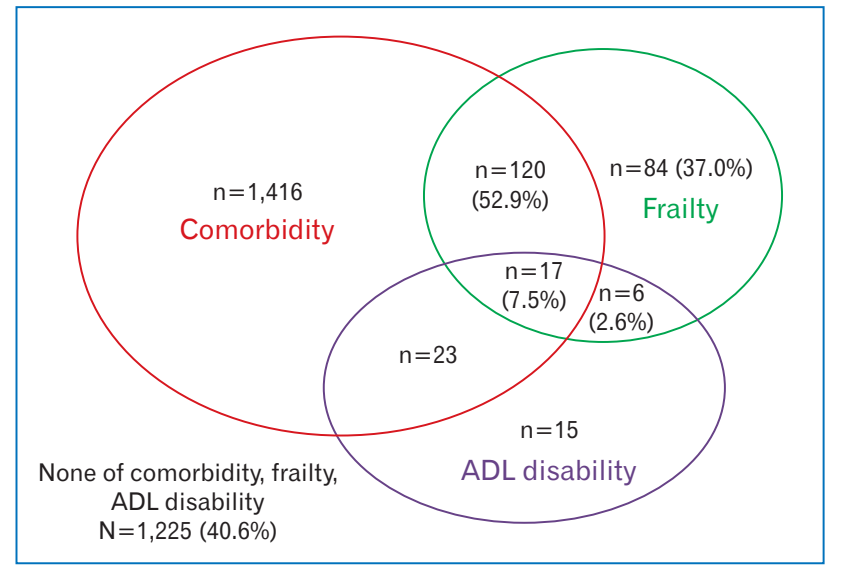

Figure 2. One-third of frailty is not associated with a comorbidity or ADL disability in community dwelling older adults: the Korean Frailty and Aging Cohort Study. ADL, activities of daily living.

grip strength measurements, as well as an assessment of physical activity are required. FI takes a long time to complete. Therefore, simple screening questionnaires will be more useful in clinical practice.

\section{FRAIL Questionnaire}

The 5-item Fatigue, Resistance, Ambulation, Illnesses, \& Loss of Weight (FRAIL) questionnaire has been well-validated worldwide. ${ }^{20)}$ The FRAIL questionnaire adopted "illness" instead of physical inactivity of the Fried frailty phenotype. A Korean version of the FRAIL (KFRAIL) scale was developed and validated. For differentiating prefrailty and frailty from robustness, the sensitivity and specificity of the KFRAIL scale were 0.90 (95\% confidence interval [CI], 0.76 to 0.97 ) and 0.33 (95\% CI, 0.22 to 0.46$)$, respectively. ${ }^{20)}$

\section{Frailty Phenotype Questionnaire}

Kim et al. ${ }^{21)}$ developed a 5-item questionnaire (The Frailty Phenotype Questionnaire) to accurately screen for the Fried frailty phenotype. The new questionnaire showed satisfactory diagnostic accuracy for 
Table 2. Comparison of frailty phenotype and frailty index

\begin{tabular}{lll}
\hline & \multicolumn{1}{c}{ Frailty phenotype } & \multicolumn{1}{c}{ Frailty index } \\
\hline Presentation & Status: frail, prefrail, robust & Score: 0 to 1 \\
Domains & Physical & Multidomains: physical, mental, cognitive, social support \\
Measurements of gait speed, handgrip strength & Needed & Not needed \\
Disability and comorbidity included in concept of frailty? & Not include disability or comorbidity & Include disability and comorbidity \\
Sensitivity for changes & Not sensitive for a change & Sensitive for a change
\end{tabular}

Table 3. English version of the Frailty Phenotype Questionnaire

\begin{tabular}{|c|c|c|c|c|}
\hline Item & Name of question & Questions & Answer options & Score \\
\hline Fatigue & Exhaustion & "During the past week, I felt that everything I did was an effort" & $\begin{array}{l}\text { (1) Rare (less than } 1 \mathrm{~d} / \mathrm{wk}) \\
\text { (2) Sometimes (1-2 d/wk) } \\
\text { (3) Often (3-4 d/wk) } \\
\text { (4) Most (over } 5 \mathrm{~d} / \mathrm{wk})\end{array}$ & $\begin{array}{l}1:(3) \text { or }(4) \\
0:(1) \text { or }(2)\end{array}$ \\
\hline Resistance & 10 Steps of stair climb & $\begin{array}{l}\text { "By yourself and not using aids, do you have any difficulty walking up } \\
10 \text { stairs without resting?" }\end{array}$ & $\begin{array}{l}\text { (1) Yes } \\
\text { (2) No }\end{array}$ & $\begin{array}{l}1:(1) \\
0:(2)\end{array}$ \\
\hline Ambulation & $\begin{array}{l}\text { Walking one lap of a } \\
\text { playground track } \\
(400 \mathrm{~m})\end{array}$ & $\begin{array}{l}\text { "Do you have any difficulty walking one lap of a playground track } \\
(400 \mathrm{~m}) \text { ?" }\end{array}$ & $\begin{array}{l}\text { (1) Unable to do it at all } \\
\text { (2) Very difficult } \\
\text { (3) A bit difficult } \\
\text { (4) Not difficult at all }\end{array}$ & $\begin{array}{l}\text { 1: (1) or (2) or (3) } \\
0:(4)\end{array}$ \\
\hline \multirow[t]{2}{*}{ Inactivity } & \multirow[t]{2}{*}{$\begin{array}{l}\text { Moderate to vigorous } \\
\text { physical activities of } \\
\text { IPAQ }\end{array}$} & $\begin{array}{l}\text { "During the past week, how often did you participate in any moderate } \\
\text { physical activities that make you slightly more breathless than } \\
\text { usual, such as rapid walking, carrying a light item, cleaning, infant } \\
\text { care (carrying, bathing)?" (excluding walking) }\end{array}$ & $\begin{array}{l}\text { (1) Never } \\
\text { (2) More than once per week }\end{array}$ & $\begin{array}{l}1:(1) \\
0:(2)\end{array}$ \\
\hline & & $\begin{array}{l}\text { "During the past week, how often did you engage in vigorous physical } \\
\text { activities, such as vigorous sports, carrying } 20 \text { kg or more weights, } \\
\text { carrying items up a set of stairs, digging, construction laboring?" }\end{array}$ & $\begin{array}{l}\text { (1) Never } \\
\text { (2) More than once per week }\end{array}$ & $\begin{array}{l}1:(1) \\
0:(2)\end{array}$ \\
\hline Loss of weight & weight loss for 1 year & "Was there an unintended weight loss of $4.5 \mathrm{~kg}$ in the past year?" & $\begin{array}{l}\text { (1) Yes } \\
\text { (2) No }\end{array}$ & $\begin{array}{l}1:(1) \\
0:(2)\end{array}$ \\
\hline
\end{tabular}

Sum of the five items score: 0 , robust; $1-2$, prefrail; $3-5$, frail.

IPAQ, International Physical Activity Questionnaire.

the Fried frailty phenotype (area under the curve $=0.89$ ) with a high sensitivity (81.7\%) and specificity $(82.5 \%) .{ }^{21)}$ The Frailty Phenotype Questionnaire is presented in Table 3. As with the Fried frailty phenotype, those with a score of "0" in the Frailty Phenotype Questionnaire are considered to be robust, while those with a score of 1 or 2 are prefrail, and those with a score 3 or more are frail.

\section{ASSESSMENT AND MANAGEMENT OF FRAILTY IN PRIMARY CARE}

Given that frailty is a common presentation in older adults, it is clear that family medicine and other primary care physicians must manage frailty ${ }^{18)}$ Primary care providers are ideally situated to incorporate the concept of frailty into their practice, as they are champions in comprehensive care. The role of primary care is crucial as family physicians can focus more on patient-oriented, comprehensive care, including biomedical and psychological care, as well as social support. Nonetheless, identification and treatment of frailty is not yet a standard practice in primary care. ${ }^{18)}$ Recognizing frailty in primary care is hindered by its insidious onset and progression, our single-system disease model, and clinicians mistaking clinical frailty for normal aging. ${ }^{22)}$

\section{Assessment and Management of Frailty in Primary Care in the United Kingdom}

Since 2017, the new General Medical Services contract in England mandates that all primary care practices use an appropriate tool to identify moderate or severe frailty for all patients aged $\geq 65$ years. ${ }^{23)}$ To identify people at risk of frailty, the electronic frailty index (eFI) was embedded in the electronic health record system. The eFI helps to screen for frailty, while the final diagnosis requiring the clinician's judgment. The eFI consists of 36 items, and it takes about 5 minutes to complete (Table 4). ${ }^{24)}$

For patients found to be severely frail, the practice must undertake a clinical review, provide an annual medication review, discuss whether the patient has fallen in the last 12 months, and provide any other clinically relevant interventions. ${ }^{24)}$

\section{Assessment and Management of Frailty in Primary Care in Canada}

The Fraser Health Authority (British, Columbia, Canada) partnered with Nova Scotia Health Authority and a private sector organization (Shannex Inc., Nova Scotia, Canada), through the Canadian Foundation for Healthcare Improvement's EXTRA program to design the Community Actions and Resources Empowering Seniors (CARES) model. CARES incorporates five strategies which are detailed below. ${ }^{18)}$ 
Table 4. List of 36 deficits contained in the electronic frailty index in UK National Health Service

\begin{tabular}{ll}
\hline \multicolumn{1}{c}{ List of 36 deficits } \\
\hline Activity limitation \\
Anaemia and haematinic deficiency \\
Arthritis \\
Atrial fibrillation \\
Cerebrovascular disease \\
Chronic kidney disease \\
Diabetes \\
Dizziness \\
Dyspnoea \\
Falls \\
Foot problems \\
Fragility fracture \\
Hearing impairment \\
Heart failure \\
Heart valve disease \\
Housebound \\
Hypertension \\
Hypotension/syncope \\
Ischaemic heart disease \\
Memory and cognitive problems \\
Mobility and transfer problems \\
Osteoporosis \\
Parkinsonism and tremor \\
Peptic ulcer \\
Peripheral vascular disease \\
Polypharmacy \\
Requirement for care \\
Respiratory disease \\
Skin ulcer \\
Sleep disturbance \\
Social vulnerability \\
Thyroid disease \\
Urinary incontinence \\
Urinary system disease \\
Visual impairment \\
Weight loss and anorexia \\
\hline
\end{tabular}

\section{1) Early identification of "at-risk" seniors}

Primary care providers (PCP) identify older people from the community who are at risk of frailty, based on their clinical judgment.

\section{2) Collaborative health assessments}

PCP and the care team evaluate the patient using a comprehensive geriatric assessment-based frailty index (FI-CGA) score to assess frailty levels.

\section{3) Wellness plans}

The summary of the CGA is shared with the patient to find out their health concerns and to aid in the creation of a wellness plan that identifies the patient's goals for enhancing their health and quality of life. The domains encouraged are exercise, socialization, and nutrition. A referral to a community health coach can be made.

\section{4) Coaching}

Patients are paired with a free-of-charge, telephone-based health coach. Seniors receive over-the-phone health coaching to track their progress in achieving their goals. This can be in terms of exercise, chronic health-care issues management, and connections to resources in the community.

\section{5) On-going assessments}

At the end of 6 months, the CGA including the clinical frailty scale and FI-CGA is repeated. After 6 months of the CARES program, the average FI score of the participants decreased by 0.03 (11\% decline), and $61 \%$ improved their FI-CGA score. These changes are significant, as it is expected that FI scores increase by $4.7 \%$ every year in older adults. At Fraser Health, the CGA is now embedded in the electronic medical records, allowing general practitioners who participate in CARES to easily access the FI-CGA scores of their patients.

\section{EVIDENCE-BASED MANAGEMENT OF FRAILTY}

There is significant evidence that suggests that frailty status might reverse to pre-frail and sometimes to a robust condition. ${ }^{25)}$

Risk factors of frailty are older age, history of cancer, hospitalization events, chronic obstructive pulmonary disease, cerebrovascular disease, and osteoarthritis. Preventable factors of frailty are higher cognitive function, absence of diabetes, higher socioeconomic status, and history of cerebrovascular disease. ${ }^{9)}$ Polypharmacy is also a significant risk factor for frailty. ${ }^{26)}$ Frailty is not considered a disease, but rather a syndrome requiring a multidomain and multidisciplinary approach. Management of frailty requires a shift from single-disease care to holistic patient care. ${ }^{27)}$

The task force of the International Conference of Frailty and Sarcopenia Research developed clinical practice guidelines that give an overview of the current evidence-based management interventions for frailty in older adults. Some recommendations are referred to as below. ${ }^{27)}$ In addition, some additional references have been added.

\section{Development of a Comprehensive Management Plan}

A comprehensive care plan for frailty should include polypharmacy, the management of sarcopenia, treatable causes of weight loss, and causes of exhaustion (depression, sleep apnea, anemia, hypotension, hypothyroidism, and vitamin B12 deficiency). ${ }^{27}$ )

\section{1) Clinical evaluation}

Exhaustion may be the result of various comorbidities such as heart failure, and a clinical evaluation is needed to exclude other causes of exhaustion.

\section{2) Avoidance of medication-related adverse events by reducing polypharmacy}

The recently developed, frailty-specific STOPP recommendation (termed STOPPFrail), outlines 27 criteria regarding medications that 
are potentially inappropriate for older adults with frailty. ${ }^{28)}$

\section{3) Other strategies}

All older persons with frailty should be assessed for visual and hearing difficulties. Those who are at risk of falling should be checked for orthostatic hypotension and syncope.

\section{Physical Activity}

Older people with frailty should be offered a multi-component physical activity program. ${ }^{27)}$ Physical activity is the most feasible way to prevent and treat frailty. Some evidence has shown that multi-component physical activity programs (combining resistance-based training with aerobic and balance training) are the most effective at managing frailty in older adults. They help to improve muscle strength, balance, and disability, as well as reduce the risk of falls. ${ }^{29)}$ Notably, group physical activity sessions were more likely to be successful in improving frailty than individual sessions according to a systematic review. ${ }^{30}$

A typical exercise regimen that may be proposed in general practice is: 20-25 minutes of activity, 4 days per week at home, comprising 15 exercises: three for strengthening arms, seven for strengthening legs, and five for balance and coordination. Each exercise should be repeated 10 times per minute, progressively reaching 15 times per minute after 2-3 months, with a rest of 30 seconds between each set. ${ }^{31)}$

\section{Nutrition and Oral Health}

Protein/caloric supplementation can be considered for persons with frailty when weight loss or undernutrition is diagnosed. ${ }^{27)}$ A Korean randomized controlled trial study showed that protein intake of $1.5 \mathrm{~g} /$ $\mathrm{kg}$ per day was the most beneficial for preventing frailty compared with a protein intake of $0.8 \mathrm{~g} / \mathrm{kg}$ per day or $1.2 \mathrm{~g} / \mathrm{kg}$ per day in prefrail or frail elderly at risk of malnutrition. ${ }^{32)}$ Nutritional/protein supplementation paired with physical activity is the most effective. ${ }^{23)} \mathrm{A}$ combination of strength exercises and protein supplementation has been shown to be the most effective and easiest intervention to implement to delay or reverse frailty in primary care. ${ }^{22)}$

\section{All persons with frailty should be offered social support as needed to address unmet care needs ${ }^{27)}$}

Practitioners should remember that social isolation is a major risk factor for the progression of frailty in older adults. ${ }^{33)}$ In Korea, contact with friends seems to be the most important social relationship to prevent frailty. Those contacting friends monthly or less were more likely to be frail compared to those in the daily contact group (adjusted odds ratio, 5.04; 95\% CI, 2.29-11.08). Interestingly, contact with family was not found to be a significant preventing factor in the study. ${ }^{34)}$

\section{CONCLUSION}

In conclusion, frailty is related to physical, psychological, cognitive, and social dysfunction. It is sometimes caused by chronic disease. Therefore, primary care providers are ideally situated to deal with frail- ty, as they are champions in comprehensive care. There is increasing global evidence for assessing and managing frailty in primary care. The frailty phenotype and FI are the most commonly used methods for identifying frailty. For frail older adults, a comprehensive care plan is needed and should aim to reduce polypharmacy and manage sarcopenia as well as other treatable causes. Older people with frailty should be offered a multi-component physical activity program that combines resistance-based training with aerobic and balance training. Protein/caloric supplementation can be considered for people with frailty when weight loss or undernutrition is diagnosed. A combination of strength exercises and protein supplementation has been found to be the most effective and easiest intervention to implement to delay or reverse frailty in primary care. All people with frailty should be offered social support to address unmet care needs.

\section{CONFLICT OF INTEREST}

No potential conflict of interest relevant to this article was reported.

\section{ORCID}

Chang Won Won: https://orcid.org/0000-0002-6429-4461

\section{REFERENCES}

1. Son DH, Park WJ, Lee YJ. Recent advances in anti-aging medicine. Korean J Fam Med 2019;40:289-96.

2. Rice DP, Fineman N. Economic implications of increased longevity in the United States. Annu Rev Public Health 2004;25:457-73.

3. Crimmins EM. Lifespan and healthspan: past, present, and promise. Gerontologist 2015;55:901-11.

4. Choi J, Ahn A, Kim S, Won CW. Global prevalence of physical frailty by Fried's criteria in community-dwelling elderly with national population-based surveys. J Am Med Dir Assoc 2015;16:548-50.

5. Collard RM, Boter H, Schoevers RA, Oude Voshaar RC. Prevalence of frailty in community-dwelling older persons: a systematic review. J Am Geriatr Soc 2012;60:1487-92.

6. World Health Organization. World report on ageing and health [Internet]. Geneva: World Health Organization; 2015 [cited 2020 May 10]. Available from: https://apps.who.int/iris/bitstream/handle/10665/ 186463/9789240694811_eng.pdf;jsessionid=68F269AAD64621FA7803 696FD4B0072B?sequence=1.

7. Michel JP, Graf C, Ma L, Ecarnot F. The end of the disease concept in geriatric medicine. Aging Med Healthc 2020;11:3-9.

8. Clegg A, Young J, Iliffe S, Rikkert MO, Rockwood K. Frailty in elderly people. Lancet 2013;381:752-62.

9. Cesari M, Prince M, Thiyagarajan JA, de Carvalho IA, Bernabei R, Chan P, et al. Frailty: an emerging public health priority. J Am Med Dir Assoc 2016;17:188-92.

10. Shim EY, Ma SH, Hong SH, Lee YS, Paik WY, Seo DS, et al. Correlation between frailty level and adverse health-related outcomes of community-dwelling elderly, one year retrospective study. Korean J Fam Med 2011;32:249-56. 
11. Fried LP, Tangen CM, Walston J, Newman AB, Hirsch C, Gottdiener J, et al. Frailty in older adults: evidence for a phenotype. J Gerontol A Biol Sci Med Sci 2001;56:M146-56.

12. Won CW, Lee S, Kim J, Chon D, Kim S, Kim CO, et al. Korean frailty and aging cohort study (KFACS): cohort profile. BMJ Open 2020;10: e035573.

13. Ministry of Health and Welfare. 2008 Living profiles of older people survey in Korea. Sejong: Korean Institute for Health and Social Affairs, Ministry of Health and Welfare; 2008.

14. Lacas A, Rockwood K. Frailty in primary care: a review of its conceptualization and implications for practice. BMC Med 2012;10:4.

15. Won CW. Frailty: its scope and implications for geriatricians. Ann Geriatr Med Res 2019;23:95-7.

16. Morley JE, Malmstrom TK, Miller DK. A simple frailty questionnaire (FRAIL) predicts outcomes in middle aged African Americans. J Nutr Health Aging 2012;16:601-8.

17. Kim S, Jung HW, Won CW. What are the illnesses associated with frailty in community-dwelling older adults: the Korean Frailty and Aging Cohort Study. Korean J Intern Med 2020 Apr 9 [Epub]. https://doi.org/ 10.3904/kjim.2019.097.

18. Theou O, Park GH, Garm A, Song X, Clarke B, Rockwood K. Reversing frailty levels in primary care using the CARES model. Can Geriatr J 2017;20:105-11.

19. Won CW, Lee Y, Lee S, Kim M. Development of Korean Frailty Index for Primary Care (KFI-PC) and its criterion validity. Ann Geriatr Med Res 2020;24:125-38.

20. Jung HW, Yoo HJ, Park SY, Kim SW, Choi JY, Yoon SJ, et al. The Korean version of the FRAIL scale: clinical feasibility and validity of assessing the frailty status of Korean elderly. Korean J Intern Med 2016;31:594600.

21. Kim S, Kim M, Jung HW, Won CW. Development of a frailty phenotype questionnaire for use in screening community-dwelling older adults. J Am Med Dir Assoc 2020;21:660-4.

22. Muscedere J, Andrew MK, Bagshaw SM, Estabrooks C, Hogan D, Holroyd-Leduc J, et al. Screening for frailty in Canada's health care system: a time for action. Can J Aging 2016;35:281-97.

23. Travers J, Romero-Ortuno R, Bailey J, Cooney MT. Delaying and reversing frailty: a systematic review of primary care interventions. Br J Gen Pract 2019;69:e61-9.

24. National Health Service England. NHS England standard general med- ical services contract [Internet]. London: National Health Service England; 2018 [cited 2020 May 10]. Available from: https://www.england. nhs.uk/wp-content/uploads/2018/01/17-18-gms-contract.pdf.

25. Pollack LR, Litwack-Harrison S, Cawthon PM, Ensrud K, Lane NE, Barrett-Connor E, et al. Patterns and predictors of frailty transitions in older men: the osteoporotic fractures in men study. J Am Geriatr Soc 2017;65:2473-9.

26. Moon JH, Huh JS, Won CW, Kim HJ. Is polypharmacy associated with cognitive frailty in the elderly?: results from the Korean frailty and aging cohort study. J Nutr Health Aging 2019;23:958-65.

27. Dent E, Morley JE, Cruz-Jentoft AJ, Woodhouse L, Rodriguez-Manas L, Fried LP, et al. Physical frailty: ICFSR international clinical practice guidelines for identification and management. J Nutr Health Aging 2019;23:771-87.

28. Lavan AH, Gallagher P, Parsons C, O’Mahony D. STOPPFrail (Screening Tool of Older Persons Prescriptions in Frail adults with limited life expectancy): consensus validation. Age Ageing 2017;46:600-7.

29. De Labra C, Guimaraes-Pinheiro C, Maseda A, Lorenzo T, Millan-Calenti JC. Effects of physical exercise interventions in frail older adults: a systematic review of randomized controlled trials. BMC Geriatr 2015; 15:154.

30. Apostolo J, Cooke R, Bobrowicz-Campos E, Santana S, Marcucci M, Cano A, et al. Effectiveness of interventions to prevent pre-frailty and frailty progression in older adults: a systematic review. JBI Database System Rev Implement Rep 2018;16:140-232.

31. Serra-Prat M, Sist X, Domenich R, Jurado L, Saiz A, Roces A, et al. Effectiveness of an intervention to prevent frailty in pre-frail communitydwelling older people consulting in primary care: a randomised controlled trial. Age Ageing 2017;46:401-7.

32. Park Y, Choi JE, Hwang HS. Protein supplementation improves muscle mass and physical performance in undernourished prefrail and frail elderly subjects: a randomized, double-blind, placebo-controlled trial. Am J Clin Nutr 2018;108:1026-33.

33. Walters K, Frost R, Kharicha K, Avgerinou C, Gardner B, Ricciardi F, et al. Home-based health promotion for older people with mild frailty: the HomeHealth intervention development and feasibility RCT. Health Technol Assess 2017;21:1-128.

34. Chon D, Lee Y, Kim J, Lee KE. The association between frequency of social contact and frailty in older people: Korean Frailty and Aging Cohort Study (KFACS). J Korean Med Sci 2018;33:e332. 